\title{
Diversity and Inclusion Practices of Selected German Multinational Firms in The Czech Republic
}

\author{
Emil Velinov ${ }^{1,2, *}$, Andreas Hilger ${ }^{3}$ \\ ${ }^{1}$ SKODA AUTO University, Czech Republic \\ ${ }^{2}$ RISEBA University of Applied Sciences, Latvia \\ ${ }^{3}$ University of Regensburg, Germany
}

\begin{abstract}
The paper investigates what specific diversity and inclusion strategies are applied across selected German multinational companies' subsidiaries located on the territory of the Czech Republic. The study suggests that in the Czech Republic the majority of the applied diversity and inclusion managerial practices are based on historical footprints in the region. Furthermore, the paper reveals that diversity and inclusion practices are significantly affected by the cultural, social norms and values in the given country. Also, paper findings show that the respective firms' subsidiaries in the Czech Republic are trying to westernize their diversity and inclusion strategies in order to attract more investors and to be more credible and prosperous. The study brings evidence that there is emerging interest and efforts by the subsidiaries in the selected emerging markets to adopt contemporary management approaches in dealing with its diverse employees in order to increase firm performance.
\end{abstract}

Keywords: diversity, inclusion, practices, German firms, Czech Republic

JEL Codes: M14, F23

\section{Introduction}

Originating from the USA, diversity management (DM) has travelled around the globe (see e.g.Klarsfeld 2014, Bendl/Henttonen/Bleijenbergh/Mills 2015). Depending on the context, DM focuses on different diversity dimensions (e.g. Konrad/Prasad/Pringle 2006) and is mainly considered to make organizations both more equality-oriented and inclusive (normative approach of DM) and financially more successful (business case of DM) (e.g. Mensi-Klarbach 
2010). As such DM is not only about meeting the needs of the individuals and increasing the wellbeing of employees but also about leveraging diversity to produce better products, services and, thus, the wealth of all stakeholders (e.g. Kirton/Greene 2015). Furthermore, societal and demographic changes trigger changes in workforce structure along with globalized markets and international competition (Mannix/Neale 2005). Thus, successful organizations are forced to manage the increasing amount of diversity (internal and external) in order to be competitive and sustainable (Soutar, 2004; Yang, 2005). In terms of multinational companies (MNCs) the question arises how they implement and realize DM strategies contextually, if their subsidiaries are subject to different cultures, socio-political frameworks and law regulations.

\section{Literature Review}

This paper aims at investigating subsidiaries of German multinational firms in the Czech Republic that are implementing and realizing diversity and inclusion managerial practices. The paper proceeds from the assumption that the context determines how diversity management is set up and implemented (relational aspect of the concept, Syed/Özbilgin 2009, Tatli/Özbilgin 2012). Thus, we expect differences in the depth and breadth of how diversity management is introduced and realized in the multinational companies' subsidiaries in the Czech Republic. We suppose that the focus of implementation may differ as well as the importance which is ascribed in the diversity and inclusion strategy to the different diversity dimensions, e.g. gender, age, nationality, sexual orientation, disability, ethnicities and minorities, religions which are all covered by the European Union antidiscrimination legislation. In fact, with this comparative project we intend to explore these differences in implementation and realization as no research results exist.

Basis for this assumption are the different historical contexts of the Czech Republic and Germany. Although these three countries are member states of the European Union nowadays, we argue that the political, societal and legal frameworks which have differed in both countries for quite some time in the $20^{\text {th }}$ century (Czech Republic as a part of Eastern Bloc countries after World War II until 1989, Austria as part of the Western European countries since World War II) still determine how diversity management is received and implemented locally by the multinational firms' subsidiaries in the respective country. As such, therefore, based on the different cultural contexts of both countries, our research questions for this joint project are to what different diversity dimensions do the multinationals subsidiaries refer to? What (theoretical) concepts do they apply [e.g. traditional binaries with term A (man, male, young, white etc.) as the norm and term not- A (woman, female, old, non-white etc.) (see Weedon 1996)] or queer perspectives (Bendl/Hofmann 2015) for managing the diversity dimensions and what dimension-related practices do these concepts trigger.

This paper is theoretically grounded on two streams of literature: On the one hand, it refers to scholarly diversity management literature which shows quite comprehensively issues of implementation (e.g Nishii/Özbilgin 2009, Tatli 2011), handling of different diversity dimensions (e.g. Konrad et al 2006, Bendl et al 2015), normative and business case of diversity (e.g. Klarbach 2010), relational and emic perspectives (e.g. Syed/Özbilgin 2009, Tatli/Özbilgin 2012), advantages and disadvantages of DM as well as its shortcomings (Bendl 2015 et a.). In order to evaluate and compare the handling of the different diversity dimensions and their related practices we also refer to the theoretical concepts underlying the construction of age, 
gender, sexual orientation, ethnicity, disability and religion as well as nationality (Velinov, 2019).

On the other hand, this paper draws on institutional logics and complexity (Marquis/Reynard 2015, Walgenbach/Mayer 2008). This organizational framework allows us to explore how past institutional arrangements may continue to shape contemporary DM strategies. In other words, an institutional logics framework makes it possible to investigate how historically-entrenched institutions and practices not only influence whether the MNCs subsidiaries take up DM in the respective countries but also how they channel attention towards particular diversity dimensions and away from others. In accordance with Maynard (2016), the underlying assumption is that "instead of being dismantled as replaced in succession, past institutional logics leave behind residual manifestation that continue to influence subsequent eras in subtle but consequential ways". Thus, according to institutional logics, the different historical sociopolitical frameworks may still influence how the MNCs subsidiaries implement human resource management practices locally and what diversity dimensions they choose to manage actively.

\section{Methodology}

As explorative study, this study examines the DM approaches of ten German multinational firms' subsidiaries on the territory of the Czech Republic from different industrial sectors classified according to the SEC industrial classification. A mixed-method design was applied for this exploration: In the first phase there were collected secondary data by referring to historical research to trace shifts in the configuration of social, political and economic infrastructures across the political regimes in both countries. This included firms' annual reports, diversity reports, corporate governance reports, companies' social media profiles, big 4 consulting firms' reports on diversity and inclusion. In the second phase we have collected secondary data both on financial figures and on the implementation of DM of the MNCs and their subsidiaries from their annual reports and websites. In the third phase, based on these collected data we have conducted online semi-structured interviews in the period of JulyOctober 2020 with diversity and inclusion and human resource managers, who are responsible persons in the subsidiaries in order to get additional information about the realization of the best practices on diversity and inclusion. Furthermore, in the paper and the handling of the different diversity dimensions and to pose questions which our secondary data collection has triggered. This mixed-method data design with primary and secondary data collection helped us to combine as many data as possible for identifying how the subsidiaries in the Czech Republic are conceptualizing and enacting DM by responding to socio-economic policies of past regimes and, thus, different cultural contexts.

\section{Results and Discussion}

Based on the primary and secondary data from all German companies (see table 1) with subsidiaries in the Czech Republic, there were withdrawn interesting findings, that have shown only some advancement of the diversity and inclusion best practices.

Table 1: List of the interviewed German firms in the Czech Republic 


\begin{tabular}{|l|l|l|}
\hline Kaufland & ZF & Deutsche Bank \\
\hline LIDL & DPD (former Geis) & Siemens \\
\hline BMW & INNOGY & \\
\hline SKODA AUTO & Mercedes & \\
\hline
\end{tabular}

Source: Own elaboration

For example, some the selected companies implied the usage of compliance management to eliminate the risks that threaten the trusts of customers and partners, that is why they use a tool which measures the acquaint of employees with legal risks and provide them with support in their daily activities. Furthermore, paper findings underline that the selected firms offer its employees a working environment that is founded on the company's culture and is protected of any form of gender, age, race, color, ethnicity, religion, sexual orientation, political opinion, disability, marital status or syndical discrimination. Interestingly, the majority of the researched firms use dynamic pricing with digital shelf labels, with Artificial Intelligence that analyze large amounts of data such as competitors' prices in order to instantly update prices and launch store promotions for attracting customers, flexible work and development, on the job and off the job, e-learning platform. In addition to social responsibility, the companies' main principles focus on customer and employee satisfaction, for example through a well-thought-out pricing policy, continuous growth and improvement, fair treatment of all entities, creating partnerships with suppliers, compliance with legislation (both employees and business partners) and internal regulations and others. For example,the German retail supermarkets present its corporate culture on the website, which according to it is based on team spirit and fair dealing - the main thing, according to the company, is employee satisfaction. Although, the German retail supermarkets in the Czech Republic do not include these activities under its "social responsibility bookmark", elements of socially responsible business can also be found in these principles. Other firms from the paper sample define social responsibility on its website primarily in connection with environmental and social responsibility.

Paper findings also refer to recruitment, retention and development of quality and motivated employees are among the basic pillars, safe working environment and fair relations without any discrimination, fair remuneration, open communication, personal development and reconciliation of work and personal life. On the top of that, majority of the researched firms apply so called Women's empowerment principles and the United Nations Global compact.

For example, Lidl has publicly asserted its commitment to diversity and inclusion with an ongoing action plan to "supports its colleagues", aligning with its" long-term diversity and inclusion strategy", includes improving its overall gender balance ratio and increasing the representation of women in senior management positions. Other reflections from the diversity and inclusion practices of the German firms, which operate in the Czech Republic are covering the following aspects:

- $\quad$ supply base must reflect the global market of our customers

- continue to seek involvement of diverse suppliers

- teaming with minority, woman-owned, veteran and small business enterprises, will help us maintain our position as one of the world's largest systems suppliers. 
Some of the selected companies have so called Diversity Day to give the employees an opportunity to take part in the discussion think about how everyone can benefit from the greatest possible diversity, because it is a success factor for innovation ang growth (\#JointheConversation ePostcard Campaign which invites employees to share their thoughts and success stories on diversity.)

\section{Conclusion}

The paper outlines very important examples and insightful contributions to the diversity and inclusion development in the businesses as it will remain of the emerging issues for many firms, which are operating on the international science. Also, the paper pins that there is still long way to go in front of the German firms with subsidiaries in the Czech Republic in terms of development and implementation of adequate and effective diversity and inclusion practices, which would increase employees' and customer engagement and motivation.

\section{Acknowledgment}

This paper is an output of the science project BTHA-AP-2020 titled „Plural Voices of German and Czech MNCs subsidiaries 'Diversity \& Inclusion Management Strategies in the Czech Republic and Germany” by University of Regensburg and SKODA AUTO University “

\section{References:}

Andrieș, A. M., Mehdian, S., \& Stoica, O. (2020). Gender Diversity, Banks 'Performance, and Stability across Central and Eastern European Countries. JEEMS Journal of East European Management Studies, 25(3), 469-502.

Bendl, Regine/Bleijenbergh, Inge/Henttonen, Elina/Mills, Albert (2015, Eds.): The Oxford Handbook of Diversity in Organizations. Oxford University Press, Oxford.

Bendl, Regine/Hofmann, Roswitha (2015): Queer perspectives on Organizing and Managing Diversity. In: Bendl, Regine/Bleijenbergh, Inge/Henttonen, Elina/Mills, Albert (Eds.): The Oxford Handbook of Diversity Studies in Organization and Management. Oxford University Press, Oxford 195-217.

Kemper, L. E., Bader, A. K., \& Froese, F. J. (2016). Diversity management in ageing societies: A comparative study of Germany and Japan. Management review. Socio-economic Studies, 27(1), 29-49.

Kirton, G., \& Greene, A. M. (2015). The dynamics of managing diversity: A critical approach. Routledge.

Klarsfeld, A. (2014, Eds.): International Handbook on Diversity Management at Work. Country Perspectives on Diversity and Equal Treatment Edward Elgar

Klarsfeld, A., Ng, E. S., Booysen, L., Castro Christiansen, L., \& Kuvaas, B. (2016). Comparative equality and diversity: main findings and research gaps.Cross Cultural \& Strategic Management, 23(3), 394-412 
Konrad,A./Prasad, P./Pringle, J. (2006, Eds): Handbook of Workplace Diversity. Sage Publication, New York.

Lena Elisabeth Kemper, Anna Katharina Bader, Fabian Jintae Froese Diversity management in ageing societies: A comparative study of Germany and Japan

Mannix, E., \& Neale, M.A. (2005). What differences make a difference? The promise and reality of diverse teams in organizations. Psychological Science in the Public Interest, 6, 2, 31-55.

Marquis, C., \& Raynard, M. (2015). Institutional Strategies in Emerging Economies. Academy of Management Annals, Volume 9: 291-335 r.

Mensi-Klarbach, h.(2010): Diversity und Diversity Management - die Business Case Perspektive : eine kritische Analyse. Kovac Verlag, Hamburg.

Nishii, Lisa/Özbilgin, Mustafa (2009): Global diversity management: towards a conceptual framework. International Journal of Human Resource Management. Vol. 18, Nr. 11, 1883-1894

Primecz, H., Havran, D., \& Lakatos, Z. (2019, July). How Does Female Presence on the Management and Supervisory Boards Impact the Performance in CEE?. In Academy of Management Proceedings (Vol. 2019, No. 1, p. 10602). Briarcliff Manor, NY 10510: Academy of Management.

Syed, Jawad/Özbilgin, Mustafa (2009): A relational framework for international transfer of diversity management practices. International Journal of Human Resource Management. Vol. 20, Nr. 12, 2435-3453

Tatli, A. \& Özbilgin, M. (2012) An emic approach to intersectional study of diversity at work: A Bourdieuan framing. International Journal of Management Reviews, 14: 180-200.

Tatli, A. (2011) A Multi-layered exploration of the diversity management field: diversity discourses, practices and practitioners in the UK. British Journal of Management, 22: 238--- 253.

Velinov, E. (2018). Diversity management in the pharmaceutical industry in central and eastern Europe. European Research Studies Journal, 21(1), 236-243.

Velinov, E. (2019). Diversity Management Practices in the US Tech Companies.

Walgenbach, Peter/Meyer, Renate E. (2008): Neoinstitutionalistische Organisationstheorie. Stuttgart: Kohlhammer 